\title{
CORRECTION
}

View Article Online

View Journal I View Issue

Check for updates

Cite this: New J. Chem., 2020, 44, 1157

DOI: $10.1039 /$ d0nj90007a

rsc.li/njc

\section{Correction: Strong metal-support interactions between palladium nanoclusters and hematite toward enhanced acetylene dicarbonylation at low temperature}

\author{
Xuemei Wei, ${ }^{\text {ab }}$ Zhanwei $\mathrm{Ma}^{\mathrm{a}}$ Jinzhi Lu, ${ }^{\mathrm{ab}}$ Xinyuan $\mathrm{Mu}^{\mathrm{a}}$ and Bin $\mathrm{Hu}^{\star \mathrm{a}}$
}

Correction for 'Strong metal-support interactions between palladium nanoclusters and hematite toward enhanced acetylene dicarbonylation at low temperature' by Xuemei Wei et al., New J. Chem., 2020, DOI: 10.1039/c9nj05493f.

The paper "Strong metal-support interactions between palladium nanoclusters and hematite toward enhanced acetylene dicarbonylation at low temperature" is corrected as follows: Fig. 3 needs to be corrected because of an error in the labelling of the Pd 3d peaks in Fig. 3c. The authors apologise for this mistake.
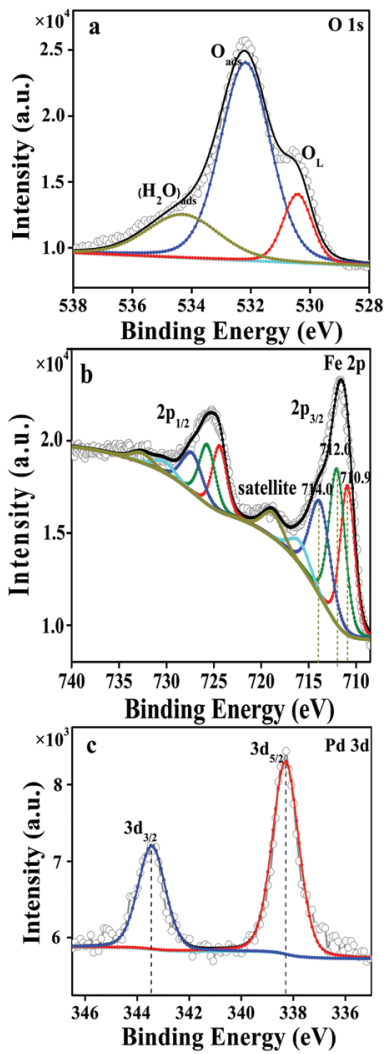

Fig. 3 XPS spectra of (a) $\mathrm{O}$ s, (b) $\mathrm{Fe} 2 \mathrm{p}_{3 / 2}$ and (c) $\mathrm{Pd} 3 \mathrm{~d}$ of $\mathrm{Pd} / \alpha-\mathrm{Fe}_{2} \mathrm{O}_{3}$.

The Royal Society of Chemistry apologises for these errors and any consequent inconvenience to authors and readers.

\footnotetext{
${ }^{a}$ State Key Laboratory for Oxo Synthesis and Selective Oxidation, Lanzhou Institute of Chemical Physics, Chinese Academy of Sciences, Lanzhou 730000, China. E-mail: hcom@licp.cas.cn; Fax: +86931 4968258, +86931 8277088; Tel: +869314968258

${ }^{b}$ University of Chinese Academy of Sciences, Beijing 100049, China
} 